TEACHING TACTIC

\title{
Exploring the Use, Impact, and Reception of the Bible through Multimodal E-Portfolios
}

\author{
Bradford A. Anderson \\ Dublin City University, Ireland
}

\section{The context}

I use this project in a large, undergraduate introductory course on the Jewish and Christian scriptures.

\section{The pedagogical purpose}

Students explore the use and impact of the Bible in ways that correspond to their own interests, and do so in a multimodal context that encourages creative engagement that is not limited to written exposition.

\section{Description of the strategy}

Students create a project exploring some aspect of the use and reception of the Bible. They are encouraged to find an example of how the Bible has been used in society and culture that relates to their own interests, whether that be music, film, literature, politics, art, etc. They use our university's e-portfolio platform, which allows students to create a digital, interactive project. This platform allows for a more engaged and creative project that includes written exposition, but which can also include hyperlinks, images, audio, and embedded video. Students use a template that has three sections which they need to populate: (1) a short biographical section where they introduce themselves (2) a project section, where they creatively highlight the results of their research on the use of the Bible, and (3) a reflection section, where they consider the project and its implications for their understanding of the Bible.

\section{Why it is effective}

When introducing students to the Bible, fostering interest in and engagement with the subject can be a challenge. This project helps students relate the subject matter to their own interests, bringing the Bible closer to the world in which they live. The results via student feedback have been very positive and the projects have been extremely creative and broad ranging, exploring the use of the Bible in areas ranging from medieval art, to political speeches, to hip-hop, to video games. The e-portfolio platform allows for a multimodal presentation. This lends itself nicely to the nature of the project (which often involves visual or aural dimensions), while also encouraging students to be creative in their presentation of the material. Finally, I give instructions on fair usage and copyright regulations regarding media, which means that students are thinking about using digital resources fairly and appropriately, as well as how to cite such resources-an increasingly important skill. 